\title{
The Phase and Magnitude of Hair Cell Receptor Potentials and Frequency Tuning in the Guinea Pig Cochlea
}

\author{
Manfred Köss|a and lan J. Russell \\ School of Biological Sciences, University of Sussex, Falmer, Brighton, BN1 9QG, England
}

Voltage responses to tones were recorded intracellularly from inner (IHC) and outer (OHC) hair cells in the basal turn of the guinea pig cochlea. Tone-evoked voltage responses were also recorded extracellularly from fluid-filled spaces adjacent to the hair cells and from supporting cells. The AC component of the OHC voltage responses to tones at frequencies between 8 and $24 \mathrm{kHz}$ and those recorded extracellularly were remarkably similar with respect to phase as a function of sound level, but the magnitude of the $A C$ response was 2-10 times larger when recorded intracellularly from an OHC. At frequencies more than half an octave below the characteristic frequency (CF), the phase of OHC AC response was independent of level, and the slope of the magnitude/level functions was $1 \mathrm{~dB} / \mathrm{db}$. At levels exceeding about $70 \mathrm{~dB}$ SPL, the slopes became less steep and depolarizing IHC and OHC DC responses appeared. At frequencies onehalf an octave below CF and at frequencies between onethird and one-half an octave above CF, notches were present in the AC/level function between 70-100 dB SPL that were accompanied by a sudden phase lag of $-180^{\circ}$. These frequency- and level-dependent characteristics were also present in relatively insensitive preparations and were attributed to a change in the phase of $\mathrm{OHC}$ excitation due to level-dependent changes in the relative stiffness of the mechanical components of the cochlear partition. At CF the detection thresholds of the OHC AC response and IHC DC response and slopes of the response/level functions were similar. At sound levels around $60 \mathrm{~dB}$ SPL, the AC signal began to phase lead, amounting to approximately $90^{\circ}$ at 70 dB SPL. Within the same range of levels, the OHC DC potentials first appeared and the IHC DC response began to saturate. At frequencies just above the CF, the phase of the AC component increased with level to a lead of about $180^{\circ}$. $\mathrm{OHC}$ and IHC tuning curves are comparable in the tip region, but they differ in that the low- and high-frequency shoulders of the OHC AC tuning curves are more sensitive by 10-30 dB SPL. On the basis of the frequency- and level-dependent

Received July 1, 1991; revised Oct. 28, 1991; accepted Nov. 6, 1991.

We thank Drs. C. Kros and A. Rüsch for their helpful comments on early drafts of the manuscript and Mr. J. Harlly for designing and building electronic equipment. This research was supported by grants from the MRC, Wolfson Foundation, and Hearing Research Trust.

Correspondence should be addressed to I. J. Russell, School of Biological Sciences, University of Sussex, Falmer, Brighton, BN1 9QG, England.

a Present address: Zoological Institute, University of Munich, Luisenstrasse 14, 8000 Munich 2, Germany.

Copyright $(\mathcal{C} 1992$ Society for Neuroscience $0270-6474 / 92 / 121575-12 \$ 05.00 / 0$ characteristics of the IHC and OHC responses, it is proposed that OHC AC potentials provide a measure of the phase and magnitude of the proposed electromechanical feedback of the cochlear partition that enhance frequency tuning in the cochlea.

The mechanosensitive channels of hair cells in the cochlea are gated when the stereocilia are displaced toward the tallest row (Hudspeth and Corey, 1977; Russell et al., 1986a,b). The precise way in which cochlear hair cells are mechanically excited is not known, but it is believed to occur as a consequence of shear displacements between the tectorial membrane and the basilar membrane, which are the two principal structural components of the cochlear partition (Davis, 1965). The rows of stereocilia of the outer hair cells (OHCs) in the mammalian cochlea are attached by their tips to the tectorial membrane and thus mechanically link the tectorial and basilar membranes. As a consequence of their strategic location in the cochlear partition, OHCs play an essential role in the frequency tuning and sensitivity of the cochlea. Following selective damage to the $\mathrm{OHCs}$, the electrophysiological and mechanical responses of the cochlea to acoustic stimulation become insensitive, linear, and broadly tuned (Liberman and Dodds, 1984; Brown et al., 1989). This finding, the measurement in situ of acoustic emissions from the cochlea (Kemp, 1978), and the discovery that, when isolated from the cochlea, the cell bodies of OHCs are capable of rapid voltage-dependent motility (Brownell et al., 1985), have led to the proposal that OIICs have an interactive role in sensory transduction in the cochlea (see Dallos, 1988, for a review). More specifically, it has been suggested that OHCs feed back energy, which overcomes viscous damping of the cochlear partition and provides the sharp frequency tuning of the cochlear responses (e.g., Weiss, 1982; Davis, 1983; Neely and Kim, 1983). It might be expected that the effectiveness of the proposed feedback depends on the mechanical properties of the basilar and tectorial membranes and on the gain and phase of the feedback process that has been associated with the OHC transducer. In the experiments reported here we have compared the magnitude and phase of voltage responses of inner (IHC) and OHCs in the basal, high-frequency turn of the guinea pig cochlea to tones within an octave of the best frequency (CF, or characteristic frequency) of the hair cells $(15-19 \mathrm{kHz})$ in an attempt to understand how electromechanical feedback contributes to the tuning of the cochlea and to deduce the mechanical behavior of the tectorial membrane in combination with the OHCs. Some of the results presented here have been published in the proceedings of a meeting (Kössl and Russell, 1990). 

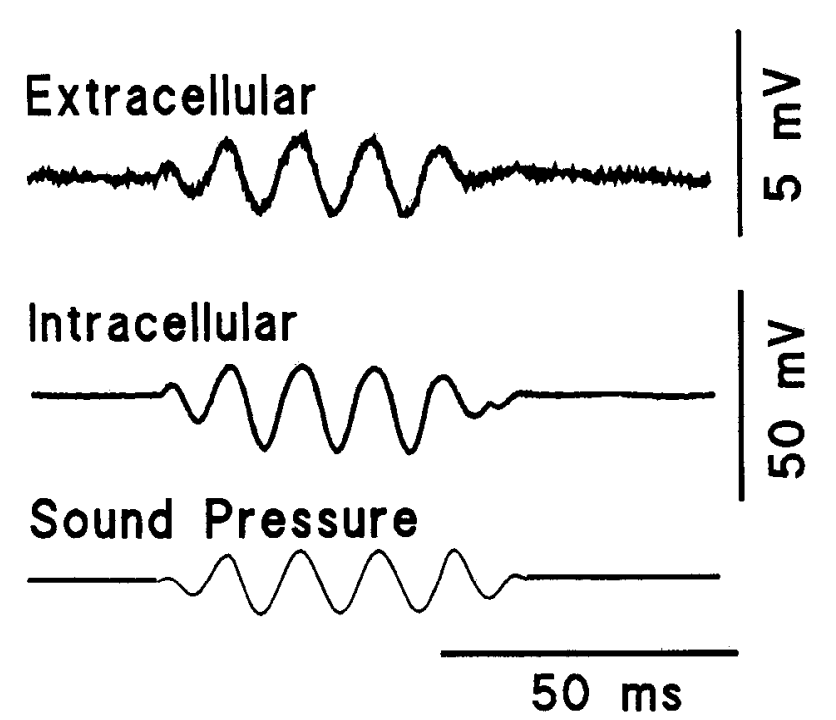

Figure 1. Extracellular and intracellular voltage responses of an $\mathrm{OHC}$ to an $80 \mathrm{~dB}$ SPL, $100 \mathrm{~Hz}$ tone. The resting potential of the OHC was $-64 \mathrm{mV}$, and the detection threshold at the CF (18 kHz) was $19 \mathrm{~dB}$ SPL.

\section{Materials and Methods}

Animal preparation and recording. Young pigmented guinea pigs weighing $180-300 \mathrm{gm}$ were used in this study. The animals were anesthetized with sodium pentobarbitone $(30 \mathrm{mg} / \mathrm{ml})$, Operidine $(1 \mathrm{mg} / \mathrm{ml})$, and Droleptan $(4 \mathrm{mg} / \mathrm{ml})$ (Evans, 1979), and a tracheal cannula was inserted. The body temperature of the guinea pig was kept at $38^{\circ} \mathrm{C}$ with a heating blanket. The heart rate was monitored through a pair of skin electrodes placed on either side of the thorax. The right cochlea was exposed through a lateral opening in the temporal bone and back illuminated by a fiber optic light guide inserted through a hole made in the basal wall of the bulla.

Micropipettes were pulled from $1 \mathrm{~mm}$ o.d. fiber-filled glass tubing and filled with $4 \mathrm{M}$ potassium acetate and $0.1 \mathrm{M} \mathrm{KCl}$. Resistances of the micropipettes ranged between 180 and $300 \mathrm{M} \Omega$ when measured in the perilymph of the scala tympani. The $\mathrm{Ag}-\mathrm{AgCl}$ reference electrode was inserted in the neck muscles.

The compound action potential (CAP) of the cochlear nerve was recorded with an electrode placed on the round window.

Signal analysis. Voltage signals from the recording pipette were amplified and directed to a two-channel lock-in amplifier (EG \& G, Princeton, model 5210 ), and they were also low-pass filtered at $3 \mathrm{kHz}$ and sampled at $0.1-0.5 \mathrm{msec}$ intervals for storage and analysis on a microcomputer (NTS). The reference signal for the lock-in amplifier was the driving voltage to the high-frequency (HF) sound delivery system. Signals from the in-phase and quadrature channels of the lock-in amplifiers were also sampled at $0.1-0.5 \mathrm{msec}$ intervals, and the phase and magnitude of the $\mathrm{AC}$ response of the voltage signal were computed either on line or from data stored on disk by the microcomputer.

Acoustic stimulation. Sound was delivered to the tympanic membrane by a calibrated closed acoustic system. High-frequency tones were dclivered through a Bruel and Kjaer $3134 \mathrm{1} / 2$ inch condenser microphone, and a Beyer DT48 dynamic ear phone was used to deliver the $100 \mathrm{~Hz}$ tones. Continuous tones and tone bursts were presented at known sound pressure level, expressed in this article in $\mathrm{dB}$ SPL (sound pressure level; $\mathrm{dB}$ re $2 \times 10^{-5} \mathrm{~Pa}$ ).

Experimental procedures. The experimental procedures were adopted from those set out in detail elsewhere (Cody and Russell, 1987; Russell and Kössl, 1991). The criteria for identifying IHCs and OHCs on the basis of membrane potentials and their voltage responses to tones and current injection were the same as those described in Cody and Russell (1987). In this series of experiments, the criterion for a sensitive preparation was one in which the change in the CAP threshold audiogram following exposure of the basilar membrane was less than $10 \mathrm{~dB}$. The frequency compensation applied to phasic voltage responses recorded through the micropipette was based on the analysis of the frequency response of the recording system according to the method first described by Baden-Kristensen and Weiss (1983) (see Cody and Russell, 1987). On the basis of this analysis, the recording system was treated as a lowpass, single-pole filter with corner frequencies between 1 and $3.5 \mathrm{kHz}$.

\section{Results}

Frequency- and level-dependent magnitude and phase relationships of $\mathrm{OHC}$ receptor potentials to $\mathrm{HF}$ tones Intracellular voltage responses from $\mathrm{OHCs}$ were identified from the resting potentials of the cells (between $-60 \mathrm{mV}$ and -75 $\mathrm{mV}$ ); from the amplitude of tone-evoked voltage responses recorded intracellularly from $\mathrm{OHCs}$, which were 2-10 times larger than those recorded from either three supporting cells or extracellularly in the organ of Corti (Fig. 1); and from the observation that current injected through the recording electrode changed the voltage responses (Dallos and Cheatham, 1991; Russell and Kössl, 1991).

Tone-evoked voltage responses were recorded intracellularly from $\mathrm{OHCs}$ and extracellularly prior to penetration. The magnitude and phase of the AC component of the intracellular and extracellular voltage response and the amplitude of the DC component of the voltage responses as functions of level and at frequencies between $10 \mathrm{kHz}$ and $20 \mathrm{kHz}$ are shown for an $\mathrm{OHC}$ in Figure 2. Inspection of Figure 2 reveals close correspondence between level functions based on intracellular recordings and those obtained immediately outside of the OHC (i.e., a further advancement of the electrode tip by about $1 \mu \mathrm{m}$ results in penetration). It was difficult to make long-term stable intracellular recordings from $\mathrm{OHCs}$, and in most cases data were collected over a wide range of frequencies when the electrode tip was located extracellularly with the tip in contact with the $\mathrm{OHC}$ membrane and intracellular responses were collected over a smaller frequency range for the duration of the stable intracellular recording (a few seconds to $10 \mathrm{~min}$ ). The limited range of intracellular recordings formed the basis of comparison with those obtained extracellularly. Examples of level functions based on intracellular recording for a brief period from an $\mathrm{OHC}$ and several minutes from an immediately adjacent supporting cell are shown in Figure 3, where it can be seen that, over a limited range of frequencies, the level dependencies of intracellular and extracellular responses are virtually identical.

The close correspondence between level functions based on intracellularly recorded voltage responses from OHCs and those recorded in the close vicinity of the $\mathrm{OHCs}$ was a constant characteristic of the 47 preparations that form the basis of this study. The close correlation between the extra- and intracellularly recorded $\mathrm{OHC}$ responses extends to the rapid changes in phase and nonmonotonic growth with increasing sound levels that can be observed at certain frequencies, for example, $12 \mathrm{kHz}$ and 20 $\mathrm{kHz}$ (Fig. 2), $12 \mathrm{kHz}$ and $24 \mathrm{kHz}$ (Fig. 3). It is possible that these level-dependent effects are due to electrical interaction between locally and remotely generated signals. If this was the case, then strong differences between intracellularly and extracellularly recorded signals might be expected to be seen as a result of changes in the relative contributions of signals from intracellular and extracellular sources at the two recording sites. Furthermore, the phase transitions and level functions change more rapidly with level than might be expected through electrical interaction between signals originating in local and distributed signal generators in the cochlea (see Dallos and Cheatham, 1989).

For the majority of stimulus frequencies spanning a range of 

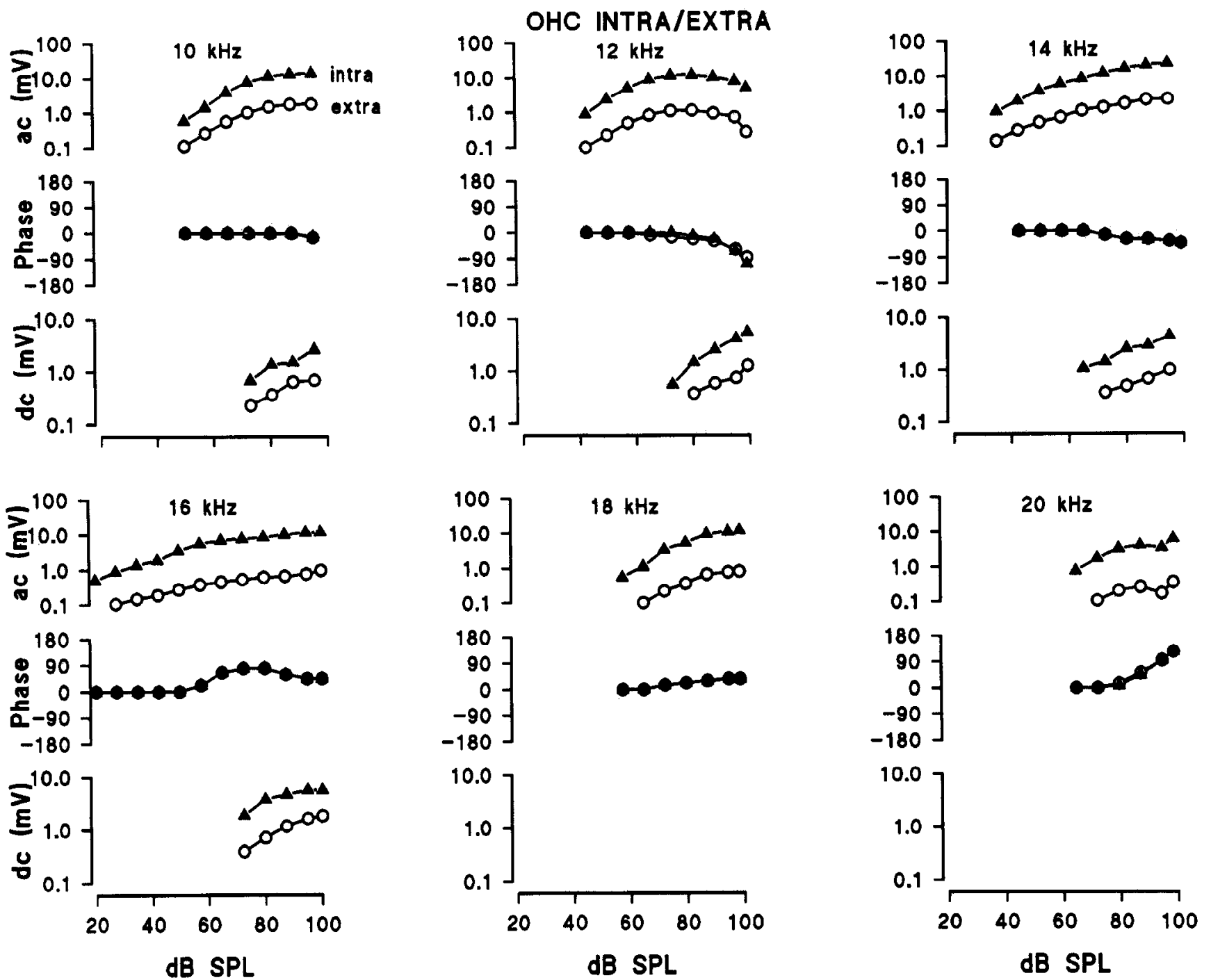

Figure 2. Tone-evoked voltage responses as functions of level (and at the frequencies shown) recorded intracellularly (solid triangles) and cxtracellularly (open circles) from an OHC. In each panel, the magnitude of the AC response (upper curves), the phase of the AC response (middle curves), and the amplitude of the DC receptor potential (lower curves) are plotted as a function of tone level. Resting potential of $\mathrm{OHC},-70 \mathrm{mV}$; detection threshold at CF (16 kHz), $20 \mathrm{~dB}$ SPL. The magnitudes of the responses are root mean square (RMS) values, positive values of phase indicate leads, and the data have been compensated for recording system and membrane time constants of $3.5 \mathrm{kHz}$ and $1.1 \mathrm{kHz}$, respectively.

about one octave below the CF of the OHC to $3 \mathrm{kHz}$ below the $\mathrm{CF}(15-19 \mathrm{kHz})$, the $\mathrm{AC}$ response grows with increasing level over a range of between 30 and $40 \mathrm{~dB}$ above the detection threshold for the signal $(7 \mu \mathrm{V})$ with a slope close to one and then saturates. The mean and SD of the initial slope of $130 \mathrm{AC}$ magnitude/level functions measured at frequencies below $\mathrm{CF}$ in 47 preparations are $1.02 \pm 0.04$. For tone frequencies below $12 \mathrm{kHz}$, the phase of the $\mathrm{AC}$ response is relatively level independent. At stimulus frequencies approximately one-half an octave below the CF of the OHC (12-13 kHz; see Figs. 2-4), the $\mathrm{AC} /$ level function is not a simple, monotonic curve, but is a triphasic function in that it grows and reaches a clear maximum (at about $70 \mathrm{~dB}$ SPL) followed by a sharp decline (minimum value at about $100 \mathrm{~dB}$ SPL), which in turn is followed by a steep rise. The secondary rise is not scen in the relationships in either Figure 2 or Figure 3 because the sound levels used in gathering this data were insufficient to elicit the effect, but the "notch" in the level function is seen in the relationships shown in Figures
4 and 7. The minimum point and secondary rise of the $\mathrm{AC} /$ level function is associated with a sharp phase lag of the $\mathrm{AC}$ response of about $-180^{\circ}$. The nonmonotonic behavior of the magnitude/level function and the associated phase lag of the $\mathrm{AC}$ response were observed at frequencies approximately onehalf an octave below the CF at intracellular and extracellular recording locations in all 47 preparations used in this study and is regarded as a consistent feature of $\mathrm{OHC}$ AC level functions at frequencies one-half an octave below CF. For tones at frequencies below the $\mathrm{CF}$ of the $\mathrm{OHC}$, positive $\mathrm{DC}$ responses of the receptor potential are first detected when the $\mathrm{AC} /$ level function begins to saturate, that is, at stimulus levels above $70 \mathrm{~dB}$ SPL (Figs. 2-4). The AC/level function does not become saturated by tones at the $\mathrm{CF}$ and at most frequencies above this within the range of levels that were employed ( $<110 \mathrm{~dB}$ SPL). At the CF and at frequencies immediately above it, the initial slopes of the $\mathrm{AC} /$ level functions are between 0.3 and 0.6 , reducing to about 0.1 at levels above $70 \mathrm{~dB} \mathrm{SPL}$, and are thus 


\section{OHC / Supporting Cell}

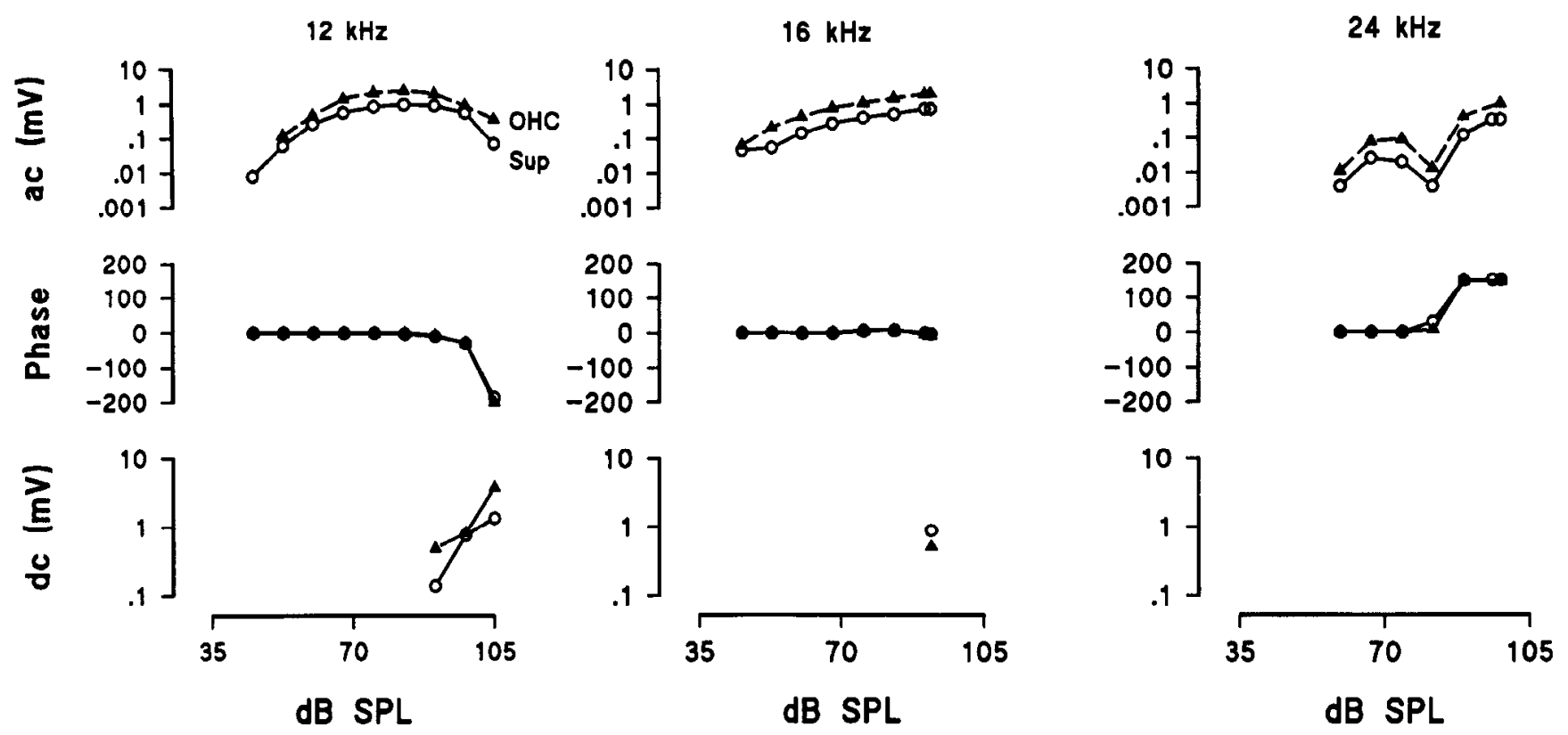

Figure 3. Tone-evoked voltage responses as functions of level (and at the frequencies shown) recorded intracellularly from an OHC (solid triangles) and a supporting cell (open circles). In each panel, the magnitude of the AC response (upper curves), the phase of the AC response (middle curves), and the amplitude of the DC receptor potential (lower curves) are plotted as a function of tone level. Resting potential of OHC, $-65 \mathrm{mV}$; resting potential of supporting cell, $-84 \mathrm{mV}$; detection threshold at CF $(19 \mathrm{kHz}), 24 \mathrm{~dB}$ SPL. The magnitudes of the responses are RMS values, positive values of phase indicate leads, and the data have been compensated for recording system and membrane time constant of $3 \mathrm{kHz}$ but not for the OHC membrane time constant, which was not determined.

more shallow and compressive than at frequencies below the $\mathrm{CF}$. Throughout the initial growth stage of the AC/level function at the $\mathrm{CF}$, the phase of the $\mathrm{AC}$ response is independent of level, but at about $60 \mathrm{~dB}$ SPL, the phase begins to lead and reaches a lead of about $+90^{\circ}$ when the tone level exceeds $70 \mathrm{~dB}$ SPL. At this level the DC response is just measurable above the recording noise floor. Phase leads were encountered at this recording site with increasing sound level for tones at $19 \mathrm{kHz}, 23$ $\mathrm{kHz}$, and $25 \mathrm{kHz}$, and a phase lag was measured at $21 \mathrm{kHz}$ (see Fig. 4). However, the frequency and level dependencies of the phase relationships of the $\mathrm{AC}$ response were far less consistent between preparations for frequencies above the CF than for frequencies below and at the $\mathrm{CF}$.

\section{The level dependence of the phase of $I H C$ and $O H C A C$ responses as a function of frequency}

A more detailed description of the frequency and level dependence of the phase of the AC response was obtained by comparing the phase of the $A C$ response for low-level tones (LLs) (40 dB SPL), with the phase of the AC response at high levels (HLs) (100 dB SPL). At LLs the OHCs are operating within the most sensitive range of their response characteristics and the phase of the AC response is independent of level. At $100 \mathrm{~dB}$ SPL, the AC response is saturating, the contribution of the proposed electromechanical feedback to the voltage responses of the OHCs is minimal (Patuzzi et al., 1989; Zwislocki, 1990), and it is presumed that the responses of the OHCs are governed by the passive mcchanical processes of the cochlea. Results from these measurements are shown in Figure 5 and are based on extracellular recordings of the $\mathrm{AC}$ responses from $\mathrm{OHCs}$ in two sensitive preparations (Fig. $5 A, B$ ), pooled results from six prep- arations with CFs between $18 \mathrm{kHz}$ and $19 \mathrm{kHz}$ (Fig. 5C), and one preparation where a loss in the CAP threshold at the CF of $20 \mathrm{~dB}$ was sustained when the basilar membrane was exposed (Fig. 5D). For tones at frequencies more than one-half an octave below the $\mathrm{CF}$, the phase of the $\mathrm{AC}$ response at LLs tends to lag the $\mathrm{HL}$ responses by between $-10^{\circ}$ and $-40^{\circ}$ (see Fig. $5 A, B$ ). At frequencies about one-half an octave below the $\mathrm{CF}$, the phase of the $\mathrm{LL} A C$ response leads the HL AC response by up to $+180^{\circ}$ and by less than this amount as the frequency of the tone approaches the CF. At the CF, the $\mathrm{LL}$ response phase lags the HL AC response by about $-90^{\circ}$, and this lag increases to $-180^{\circ}$ at frequencies just above $C F$. The $L L$ response also phase lags the HL AC response at frequencies around one-half an octave above the $C F$, but at frequencies just below one-half an octave above the $C F$, the $L L A C$ response leads the $H L A C$ response by up to $+180^{\circ}$. Similar W-shaped phase difference/frequency curves were plotted for intracellular and extracellular recording sites in six preparations, and the means of all six measurements are shown in Figure $5 C$. In sensitive cells the phase of the LL signal lags the HL signal at $\mathrm{CF}$, but not in insensitive preparations where the phase of the LL CF response may be independent of level or leads the HL response by less than $+20^{\circ}$. On the basis of the phase measurements of $\mathrm{OHC} A C$ responses measured in a total of 47 preparations, the LL response always leads the HL response at frequencies about one-half an octave below CF and again at frequencies between one-third and onehalf an octave above CF, although the phase relationships are more variable between preparations above CF. These phase lags are robust phenomena in that they are also present in insensitive and poorly tuned preparations. The $90^{\circ}$ phase lag at CF and the $180^{\circ}$ phase lag at frequencies within $1-2 \mathrm{kHz}$ above $\mathrm{CF}$ of the 

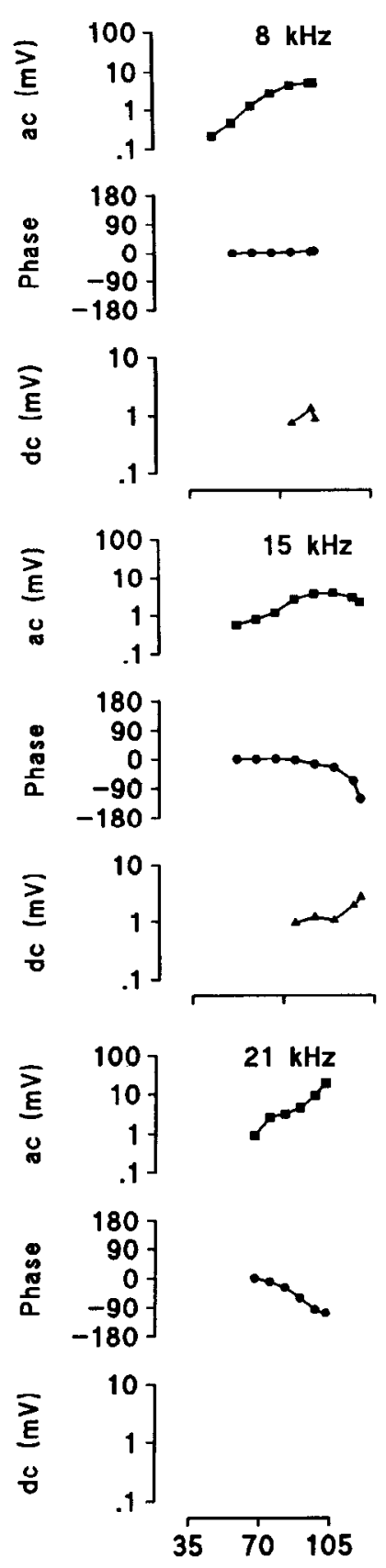

LL response with respect to the $H L$ response are characteristic of sensitive well-tuned $\mathrm{OHCs}$, but similar phase lags were never observed in preparations where a threshold loss of $>20 \mathrm{~dB}$ had been sustained at the CF.

\section{Comparison between $I H C D C$ and $O H C A C$ voltage responses to tones}

With present recording methods it is not possible to make intracellular recordings from an $\mathrm{IHC}$ and an adjacent $\mathrm{OHC}$ at the same time. However, essentially the same data can be collected by a single micropipette placed extracellularly close to an IHC. In this position, the $\mathrm{AC}$ responses are dominated by voltages generated by the OHCs (Russell and Sellick, 1983; Cody and Mountain, 1989); the amplitude and phase of the AC response
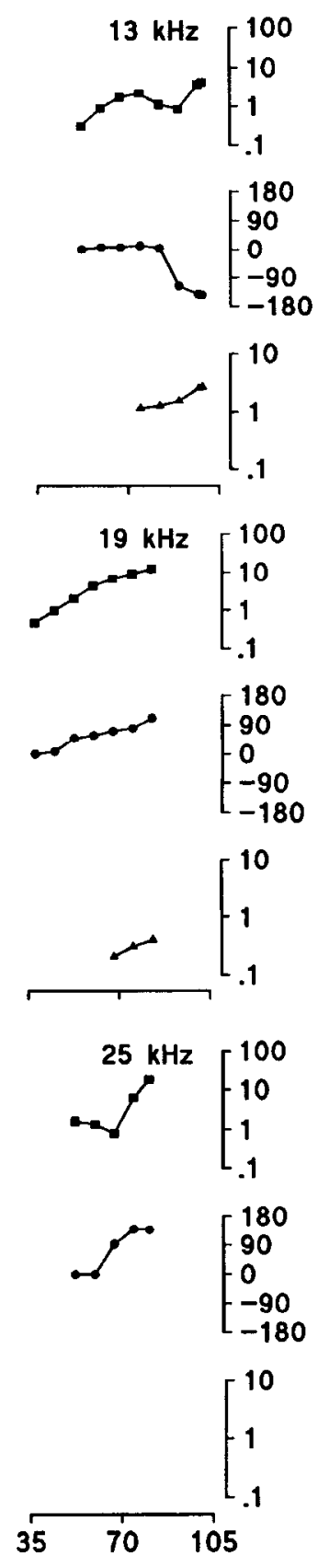

Figure 4. Magnitude, phase, and DC response/level functions recorded extracellularly from an $\mathrm{OHC}(\mathrm{CF}, 18 \mathrm{kHz})$ at the frequencies indicated. The panels are arranged as in Figure 3. The magnitude is compensated for the singlepole, low-pass filtering of the recording electrode (corner frequency, $3.5 \mathrm{kHz}$ ).

as functions of level are almost identical to those recorded intracellularly from OIICs and adjacent supporting cells (compare Figs. 2-4 with Figs. 6, 7), and the level-dependent behaviors of the extracellular DC responses closely resemble those based on DC responses recorded intracellularly and extracellularly from IHCs (see Russell and Sellick, 1978, and Fig. 6). On this basis, attempts were made to describe the extracellular potentials in terms of the IHC DC and OHC AC responses from potentials recorded immediately adjacent to IHCs. In Figure 6, the amplitude of the DC response of the extracellular IHC receptor potential and the magnitude and phase of the extracellular AC response of the $\mathrm{OHC}$ receptor potential to tones as functions of sound level are compared for tones at frequencies within an octave of the CF of the IHC $(18 \mathrm{kHz})$. The frequency- and level- 
Figure 5. Phase difference between OHC $A C$ responses measured extracellularly at $100 \mathrm{~dB}$ SPL and $40 \mathrm{~dB}$ SPL as a function of frequency. The phase of the $100 \mathrm{~dB}$ SPL response is set to zero. Positive values indicate that the 40 dB SPL response leads the $100 \mathrm{~dB}$ SPL response, and negative values indicate that the $40 \mathrm{~dB}$ SPL response lags the $100 \mathrm{~dB}$ SPL response. $A$ and $B$ are from single OHCs, $C$ represents the pooled responses from six $\mathrm{OHCs}$, and $D$ is from an OHC where a threshold loss of 20 $\mathrm{dB}$ was incurred when the basilar membrane was exposed. The phase/frequency functions comprising $C$ were normalized to a common $\mathrm{CF}$.
A

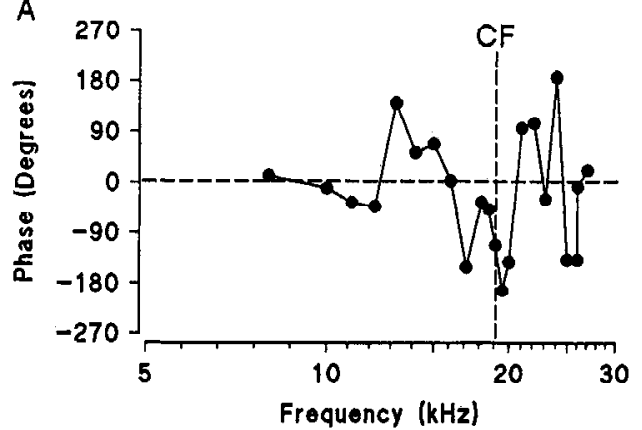

C

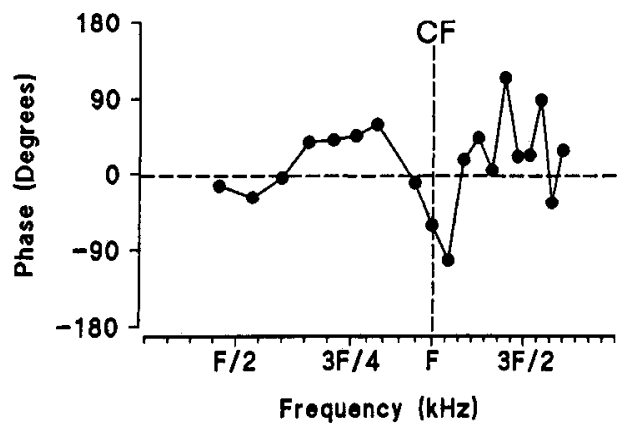

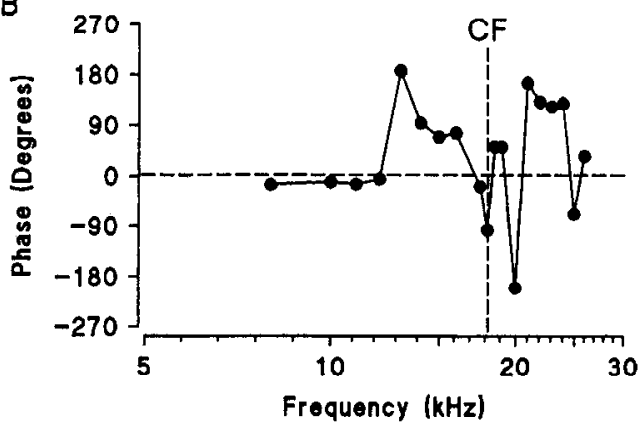

D

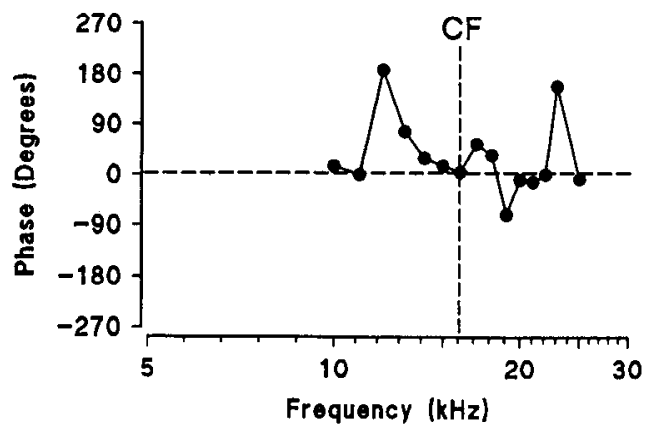

dependent characteristics of the amplitude and phase of the OHC AC response (upper two curves in each trio of curves) are very similar to those shown in Figures 2-4. For frequencies below the $\mathrm{CF}$, the level dependence of the IHC DC response is similar to that of the $\mathrm{OHC} \mathrm{DC}$ response recorded intracellularly from, or just outside of, $\mathrm{OHCs}$ in that it is first detected when the $\mathrm{OHC} \mathrm{AC}$ response component begins to saturate. This occurs when the tone levels exceed $70 \mathrm{~dB}$ SPL, and this level is reduced for frequencies approaching the $\mathrm{CF}$. At the $\mathrm{CF}$, the level at which the IHC DC responses can be detected is the same as that of the OHC AC response (see Fig. $6,18 \mathrm{kHz}$ ) and the IHC DC response/level function has a slope of about 0.3 over a 30 $40 \mathrm{~dB}$ range from about $20 \mathrm{~dB}$ SPL. Over this range of levels at $\mathrm{CF}$, the phase of the $\mathrm{OHC} \mathrm{AC}$ response is level independent, but above about $60 \mathrm{~dB}$ SPL, the phase begins to lead and reaches a maximum phase lead of about $+90^{\circ}$ at $75 \mathrm{~dB}$ SPL. This is when the $\mathrm{OHC} A C$ response component saturates. The $\mathrm{IHC} D C$ response begins to saturate at about $60 \mathrm{~dB}$ SPL, which is when the phase of the $\mathrm{OHC} \mathrm{AC}$ response begins to lead. At frequencies above the $C F$, the IHC DC response increases with frequency until frequencies are reached when the IHC DC response is no longer detected within the range of stimulus levels employed. Similar results to those described in Figure 6 were obtained by comparing extracellular recordings from OHCs with intracellular recordings from adjacent IHCs. The experimental sequence consisted of first making extracellular recordings from an $\mathrm{OHC}$ followed by intracellular recordings from an IHC with no apparent loss of sensitivity in the cochlear audiogram between recording locations. A comparison between the magnitude and phase of $\mathrm{AC}$ responses recorded from an $\mathrm{OHC}$ and the amplitude of $\mathrm{DC}$ responses recorded from a nearby IHC as functions of level are shown in Figure 7 for frequencies at $13 \mathrm{kHz}, 18 \mathrm{kHz}$ (CF), and $24 \mathrm{kHz}$. The results shown in Figure 7 are remarkably similar to those shown in Figure 6 for the extracellular recordings. The principal difference is that the initial slopes of the DC functions for the $12 \mathrm{kHz}$ and $18 \mathrm{kHz} \mathrm{DC} /$ level functions are close to 2 rather than 1 or less as in the extracellular recordings.

\section{$I H C D C$ and $O H C A C$ isoresponse tuning curves}

Almost identical isoresponse tuning curves were derived from $A C$ responses recorded both intra- and extracellularly from the same $\mathrm{OHC}$ (Fig. 8). The AC recordings were compensated for the time constants of the recording system, and for $\mathrm{AC}$ tuning curves derived from intracellularly recorded responses, the hair cell membrane time constant was also taken into consideration. The latter responses were estimated from the rise time of the membrane potential to $0.1-0.4 \mathrm{nA}$ current steps (see Cody and Russell, 1987). Isoresponse tuning curves based on IHC DC responses recorded extracellularly (Fig. 9A) and intracellularly (Fig. 9B) were compared with tuning curves based on extracellularly recorded $\mathrm{AC}$ responses from adjacent $\mathrm{OHCs}$. The comparisons were based on intracellularly and extracellularly recorded voltage responses from IHCs and $\mathrm{OHCs}$ in the same preparation and without measurable changes in cochlear sensitivity between recordings. The parameters of the $\mathrm{OHC} \mathrm{AC}$ and IHC DC tuning curves obtained in this series of experiments, including those shown in Figures 8 and 9, are given in Table 1 . The IHC and OHC tuning curves differ most noticeably in that the low-frequency shoulder of the OHC AC tuning curves are up to $25 \mathrm{~dB}$ (mcan, $14 \mathrm{~dB}$ ) morc scnsitive than those for the IHC DC tuning curves and secondary peaks appear on the $\mathrm{HF}$ slopes of the $\mathrm{OHC} \mathrm{AC}$ tuning curves (see arrows in Fig. $9 A, B)$.

\section{Discussion}

Phase and magnitude of $\mathrm{OHC}$ and $\mathrm{IHC} A C$ receptor potentials as indicators of electromechanical feedback

If the OHCs operate in a true electromotor feedback loop, then they will contribute to their own responses and hence to the mechanical responses of the cochlear partition. The net me- 

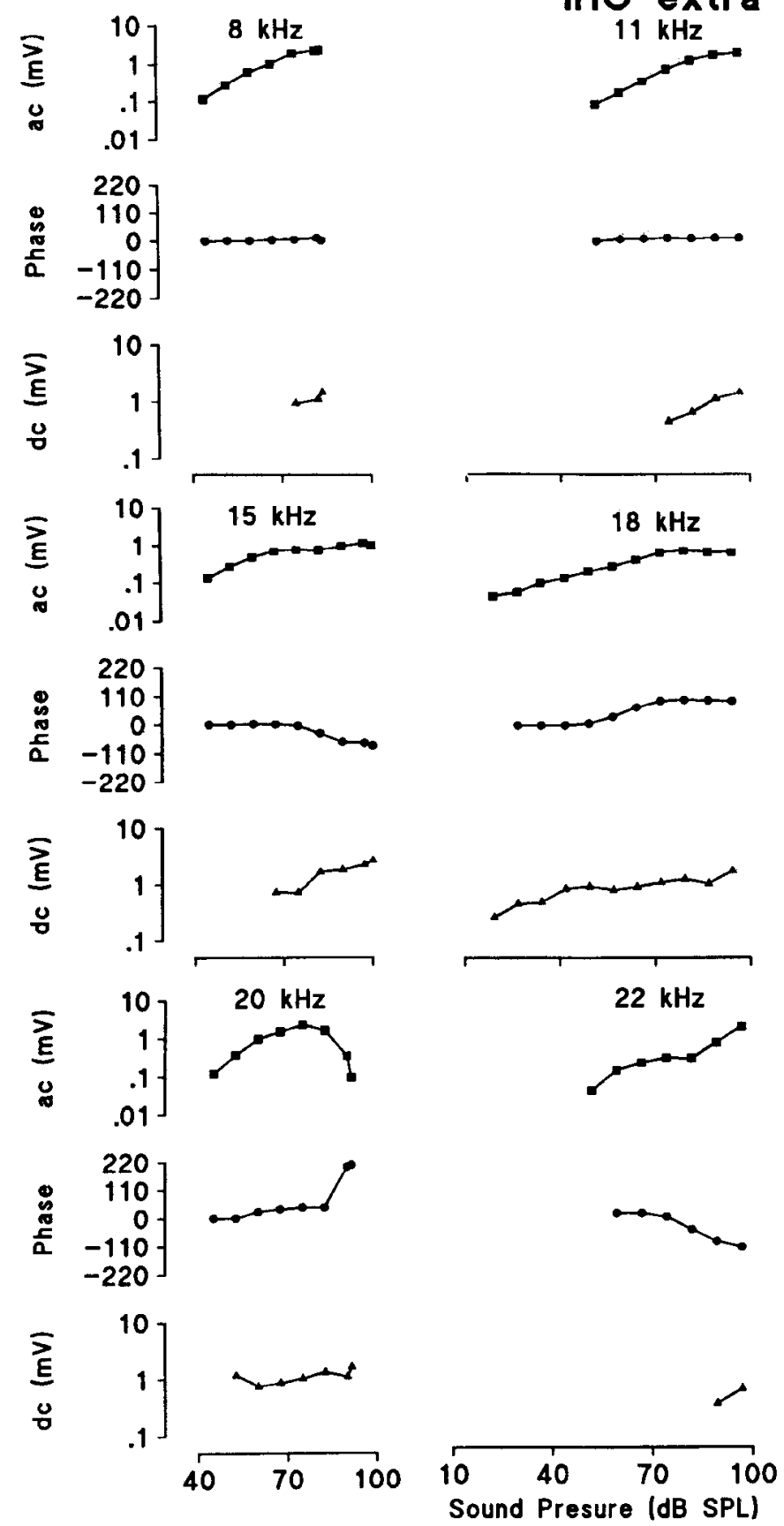

chanical response of the cochlear partition, that is, the radial shear displacement between the tectorial and basilar membranes, is detected by the IHCs (Davis, 1965) and reflected in the DC receptor potentials of the IHCs (Russell and Sellick, 1978) and in the firing pattern of the auditory nerve fibers (Kiang et al., 1965). OHCs might be expected to make a significant contribution to the mechanical properties of the cochlear partition at low and moderate levels of the acoustic stimulus that is within the most sensitive region of the $\mathrm{OHC}$ transducer function (Cody and Russell, 1987). For tone levels within this range, the magnitude of the $\mathrm{AC}$ response of the $\mathrm{OHC}$ receptor potential might provide a measure of the feedback contributed by the OHCs to the mechanics of the cochlear partition and the phase of the $\mathrm{AC}$ response relative to that of the passive mechanics of
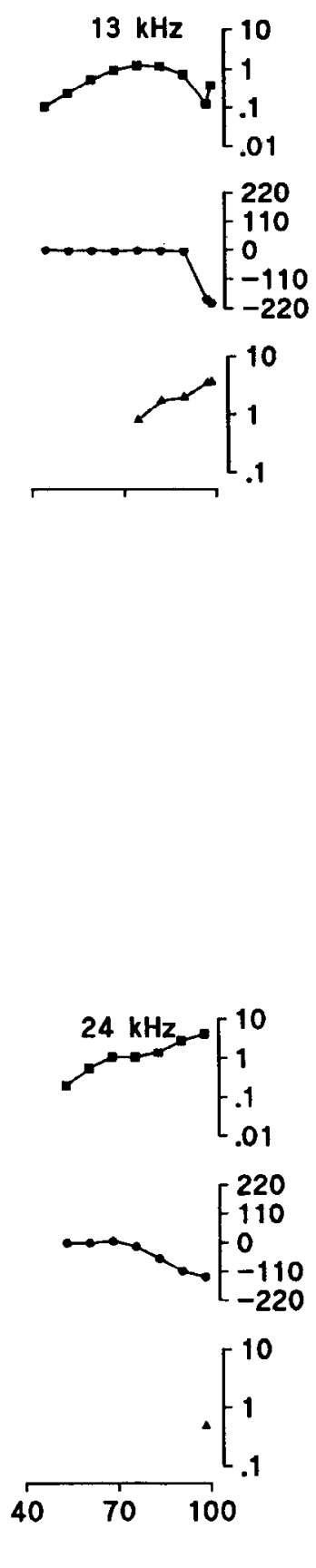

Figure 6. Magnitude, phase, and DC response/level functions recorded extracellularly close to an IHC (CF, 18 $\mathrm{kHz}$ ) at the frequencies indicated. The panels are arranged as in Figure 3. The magnitude is compensated for the lowpass filtering of the recording electrode (corner frequency, $3 \mathrm{~Hz}$ ). the basilar membrane indicates the sign of the feedback. For high levels of the acoustic stimulus, the OHC transducer is saturated and the mechanical responses of the basilar membrane and the voltage responses of the OHCs are governed by the passive mechanical properties of the basilar membrane (Patuzzi et al., 1989; Zwislocki, 1990). If these assumptions are made, the amplitude of tone-evoked IHC DC responses and the phase and magnitude measurements of $\mathrm{OHC} \mathrm{AC}$ responses reported here may be taken to indicate that electromechanical feedback from the OHCs is negative and tends to oppose shear displacement between the basilar membrane and tectorial membrane at frequencies on the HF and low-frequency shoulders of the tuning curve. This is because at these frequencies IHC DC responses do not appear until the $\mathrm{OHC} \mathrm{AC}$ responses begin to 
OHC extra / IHC intra

Figure 7. Magnitude, phase of AC responses recorded extracellularly from an $\mathrm{OHC}$ (open circles), and the amplitude of DC responses recorded intracellularly from an adjacent IHC (CF 18 $\mathrm{kHz}$ ) (open triangles) as functions of level at the frequencies indicated. The magnitudes of the extracellular AC responses are corrected for the low-pass filtering of the recording electrode (corner frequency, $3 \mathrm{kHz}$ ).

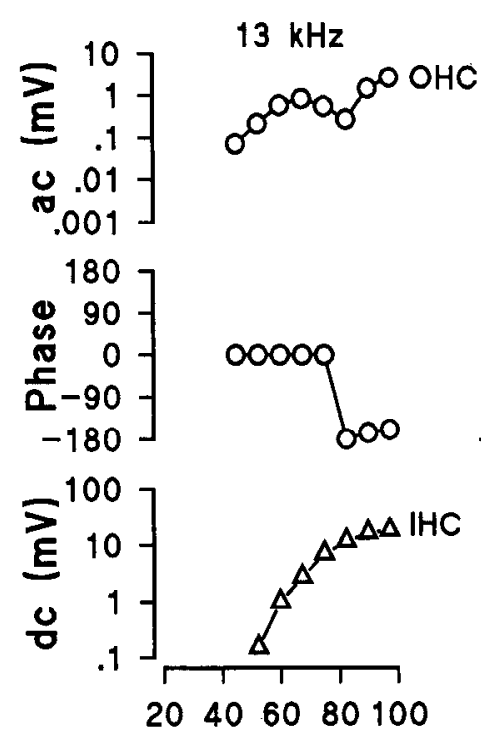

dB SPL
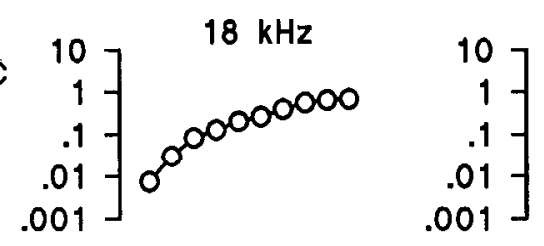

$24 \mathrm{kHz}$
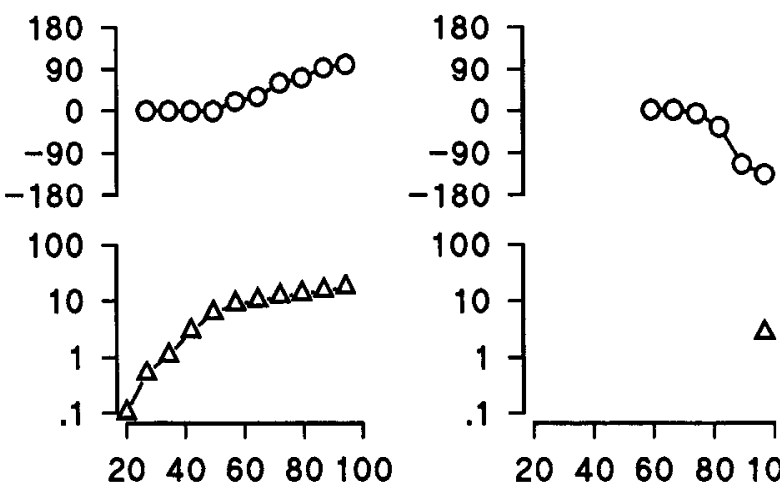

dB SPL
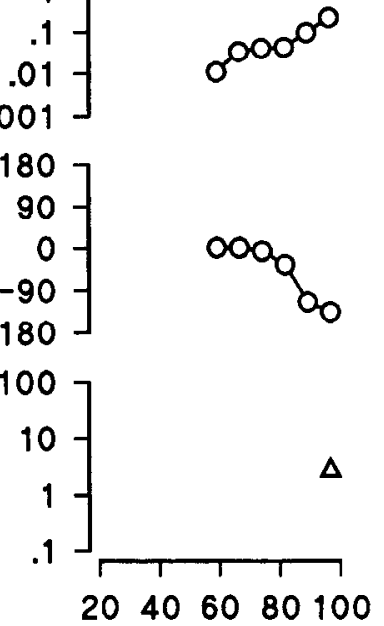

dB SPL

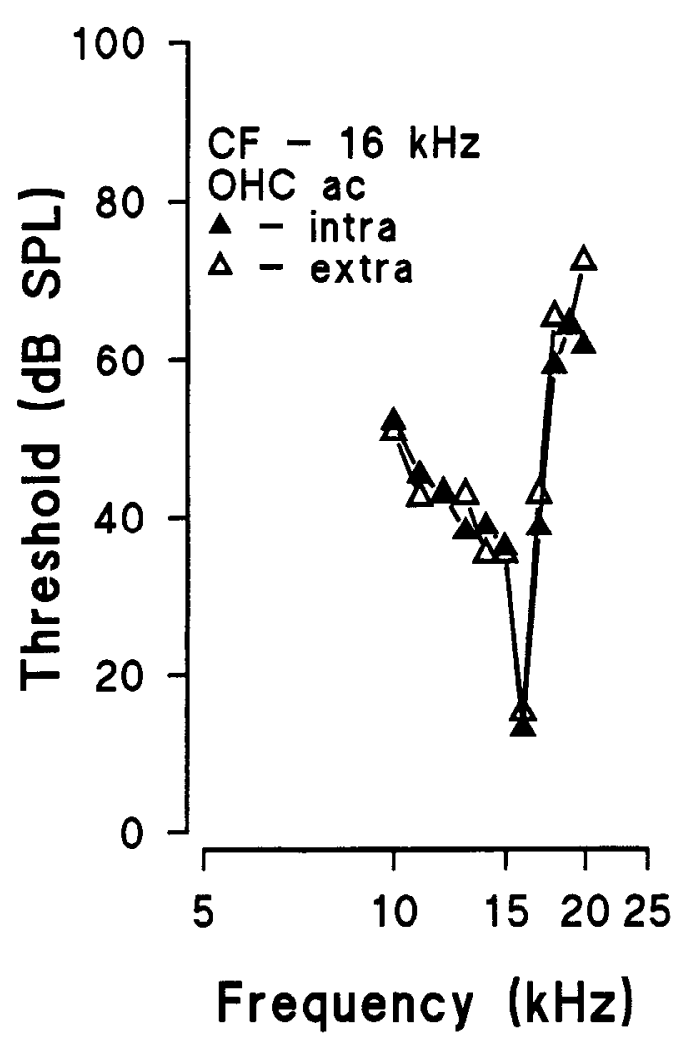

Figure 8. Isoresponse AC tuning curves measured intracellularly and extracellularly from the same OHC. The isoresponse thresholds were $0.1 \mathrm{mV}$ extracellular and $1 \mathrm{mV}$ intracellular when the AC magnitude had been corrected for the recording system and $\mathrm{OHC}$ membrane time constants $(3.5 \mathrm{kHz}, 1.2 \mathrm{kHz}$, respectively). OHC resting membrane potential, $-70 \mathrm{mV}$. Threshold loss on exposing the basilar membrane was less than $5 \mathrm{~dB}$ SPL. saturate at $20-40 \mathrm{~dB}$ SPL above the level at which $\mathrm{OHC}$ AC responses can first be detected (see Figs. 6, 7).

In contrast, at the CF and in sensitive (Figs. 5-7), but not insensitive, preparations (Fig. $5 D$ ), OHC AC responses begin to phase lead at levels above about $60 \mathrm{~dB}$ SPL and asymptote at about $90^{\circ}$. The appearance of the phase lead is associated with a reduction in the slope of the IHC DC/level function. It is suggested that for LLs and moderate levels, the phase of OHC feedback changes from being $-180^{\circ}$ out of phase with basilar membrane displacement (i.e., negative feedback) for frequencies away from the $\mathrm{CF}$ to being $-270^{\circ}$ out of phase with basilar membrane displacement (in phase with basilar membrane velocity; positive feedback) at the CF. Thus, the OHCs provide amplification of basilar membrane motion at the $\mathrm{CF}$, which diminishes when the OHC transducer begins to saturate. It is proposed that the feedback is responsible for the enhanced sensitivity of IHC and OHC response/level functions at the CF for LLs and moderate tone levels. With increasing tone levels the OHC transducer begins to saturate, the $90^{\circ}$ phase lag becomes eroded and the slopes of the level functions become reduced as the motion of the basilar membrane becomes increasingly dominated by the passive elements of the cochlear partition. The observations presented in this article accord with a model of frequency tuning in which OHCs contribute negative feedback that reverses through a frequency-dependent phase delay to positive feedback at the CF (Mountain et al., 1983). That is, electromotor feedback from the OHCs opposes basilar membrane displacement at frequencies away from the CF, but augments basilar membrane velocity at the CF.

At frequencies just above CF, at about one-half an octave below $\mathrm{CF}$ and between one-third and one-half an octave above $\mathrm{CF}$, the HL OHC AC response is up to $180^{\circ}$ out of phase with the I.I. response and the phase transitions are associated with magnitude minima or "notches" in the fundamental AC re- 
A

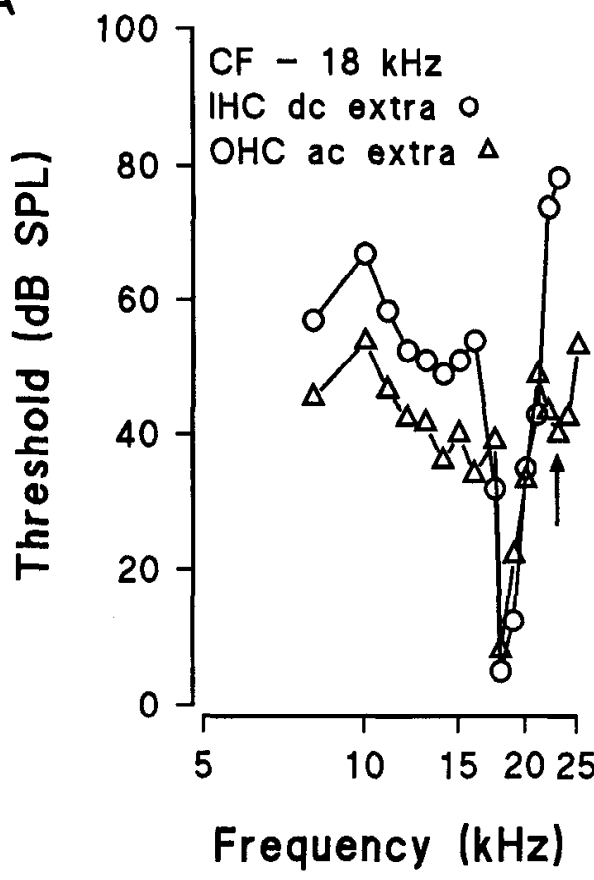

B

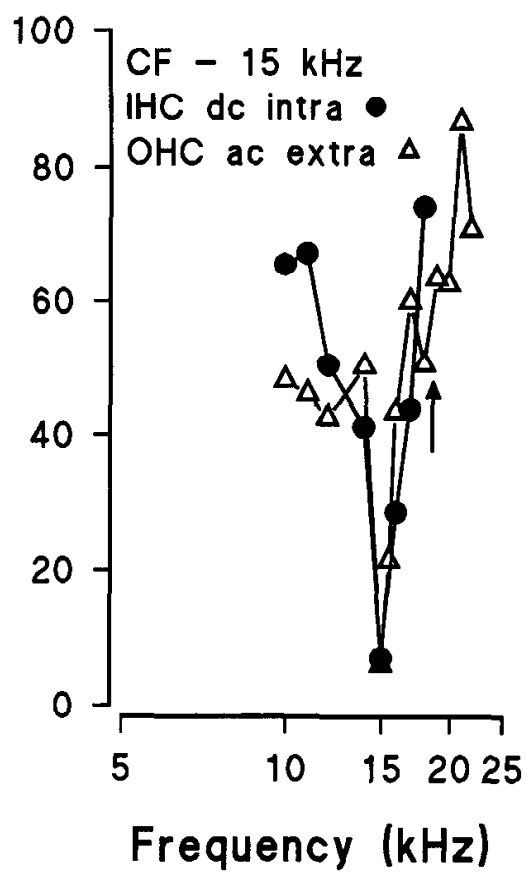

Figure 9. Isoresponse tuning curves measure extracellularly for $\mathrm{OHCs}$ and extracellularly $(A)$ and intracellularly $(B)$ for IHCs. $A$ and $B$ are from different preparations. The isoresponse thresholds of the extracellular OHC AC tuning curves and the extracellular IHC DC tuning curves were $0.1 \mathrm{mV}$. The isoresponse threshold for the intracellular IHC DC tuning curve was $1 \mathrm{mV}$, and the IHC resting potential was $-45 \mathrm{mV}$. Threshold loss following exposure of the basilar membrane was less than $5 \mathrm{~dB}$ SPL. The AC responses were compensated for the recording system time constant $(3 \mathrm{kHz})$. sponse/level functions (see Figs. 2, 4, 6, 7). It is suggested that these $180^{\circ}$ phase jumps are not related to the feedback process associated with frequency tuning because they survive desensitization and loss of frequency tuning in the cochlea (see Fig. $5 D$ ). These observations are in accordance with the results of similar measurements made on the gerbil cochlea by Zwislocki $(1988,1990)$. Phase jumps and "notches" have been observed in the fundamental magnitude functions of IHCs but not $\mathrm{OHCs}$ in the apical turns of the guinea pig cochlea (Dallos and Cheatham, 1989), and magnitude minima and phase jumps have been observed in basilar membrane mechanics (Patuzzi et al., 1984). The $180^{\circ}$ phase jumps may indicate that the direction of basilar membrane displacement associated with $\mathrm{OHC}$ excitation has become reversed. OHCs are excited by displacement of the stereocilia bundle toward the tallest row (Russell et al., 1986b), and according to a recent mechanical model of the cochlear partition (Zwislocki, 1986), this can be achieved by displacements of the basilar membrane toward either the scala vestibuli or the scala tympani, depending on the relationship between the rotational stiffness of the stereocilia bundle and the radial stiffness of the tectorial membrane. A change in the relationship between the rotational stiffness of $\mathrm{OHC}$ stereociliar bundles and the radial stiffness of the tectorial membrane, possibly as a consequence of a level-dependent change in the mechanical impedance of elements within the cochlear partition, could reverse the direction of excitation as proposed by Zwislocki $(1986,1988)$ and Mountain and Cody (1989). For example, the radial stiffness of $\mathrm{OHC}$ stereocilia bundles is reduced following intense mechanical stimulation (Saunders and Flock, 1986).

\section{Frequency and level dependence of the $O H C A C$ response: comparison with mechanical and neural responses of the cochlea}

The frequency and level dependence of the phase relationships of the $\mathrm{OHC} \mathrm{AC}$ response is similar to those of the response phases measured from other sensory and mechanical components of the cochlea. On the basis of phase locking of lowfrequency spike discharges in the auditory nerve, Anderson et al. (1971) were the first to observe that the response phase of the auditory periphery was dependent on level. They found that for frequencies below the $\mathrm{CF}$ of the fiber, the response phase increasingly lagged with increasing level and that above the $C F$, the phase of the response increasingly led with increasing level. Similar, systematic changes in phase with level and frequency

Table 1. Filter characteristics of IHCs and OHCs in the basal coil of the cochlea

\begin{tabular}{lcc} 
& IHC & OHC \\
\hline Number of cells & 4 & 4 \\
Range of best frequencies (kHz) & $15-19$ & $15-19$ \\
$Q_{\text {ladi }}$ (center frequency/bandwidth 10 dB above tip) (mean $\left.\pm \mathrm{SD}\right)$ & $7.5 \pm 1.3$ & $7.9 \pm 1.0$ \\
HF slope (dB/octave) (mean \pm SD) & $544 \pm 141$ & $558 \pm 166$ \\
Low-frequency slope (dB/octave) (mean $\pm \mathrm{SD}$ ) & $170 \pm 100$ & $211 \pm 42$ \\
Tip to shoulder (dB) (mean \pm SD) & $54 \pm 8$ & $40 \pm 7$
\end{tabular}

The OHC parameters are based on tuning curves for the AC component, corrected for the attenuation produced by the membrane time constant and recording system, whereas the IHC parameters are derived from tuning curves of the DC component. 
around the CF have been observed for intracellularly recorded receptor potentials in hair cells in the apical turn of the guinea pig by Dallos (1986) and in the mechanical responses of the basilar membrane (Rhode, 1971; Rhode and Robles, 1974; Geisler and Rhode, 1982; Sellick et al., 1982; Patuzzi et al., 1984; Ruggero et al., 1992) observed that progressive phase leads with increasing level at the CF were not present in the basilar membrane mechanics for frequencies that produce linear input/output functions in the tail or for frequencies in the tip of the tuning curve in preparations that suffered severe losses in sensitivity during experimentation. Ruggero and Rich (1991a) observed that the reversible loss of tuning and sensitivity of the chinchilla basilar membrane motion following intravenous administration of furosimide was associated with a phase lag in basilar membrane responses measured at the CF. Thus, observations on the frequency and level dependency of $\mathrm{OHC} \mathrm{AC}$ responses presented in this article are similar in many respects to measurements of basilar membrane motion and support the widely held notion that responses of OHCs largely determine those of the basilar membrane.

\section{Hair cell isoresponse tuning curves; comparison with mechanical and neural tuning curves}

It was suggested above that, at low sound levels, the $\mathrm{AC}$ response of the OHC receptor potential provides a measure of the mechanical feedback to the cochlear partition and the DC response of the IHC receptor potential is an indicator of the net effect of this feedback on the mechanics of the cochlear partition. On the basis of this, it might be expected that the isoresponse frequency tuning curves of IHCs and OHC may differ from each other and from isoresponse tuning curves of the basilar membrane mechanics. In these experiments, it was possible to obtain a total of four sets of isoresponse tuning curves from adjacent IHCs and OHCs without a measurable change in cochlear sensitivity between and following the recordings. The characteristics of isoresponse tuning curves based on these recordings were very similar in the tip region. The $Q_{10 \mathrm{~dB}}$ and $\mathrm{HF}$ and lowfrequency slopes were similar to those measured for hair cells, primary afferent fibers, and the basilar membrane in the basal turn of the guinea pig cochlea (Russell and Sellick, 1978; Sellick et al., 1982, 1983; Brown et al., 1983; Cody and Russell, 1987; Nuttall et al., 1991). In all respects, the tuning curves of IHCs and nerve fibers are almost identical, which may indicate that synaptic transmission across the IHC afferent synapse is frequency independent, at least for frequencies above a few kilohertz. However, IHC and $\mathrm{OHC}$ tuning curves are dissimilar in that the difference between the tip and the low-frequency "tail" of $\mathrm{OHC}$ tuning curves is about $15 \mathrm{~dB}$ less than that of IHC and neural tuning curves (Cody and Russell, 1987; see Fig. 7, Table 1). In this respect, $\mathrm{OHC}$ tuning curves resemble isodisplacement tuning curves of the basilar membrane, where it has been observed that the sharp transition between the tip and the lowfrequency tail, which characterizes IHC and neural tuning curves, is absent (Sellick et al., 1983). It remains to be seen if the introduction of more sensitive laser Doppler velocimetry and optical techniques will result in basilar membrane isoamplitude tuning curves that more closely resemble neural tuning curves. The limited data currently available do not resolve this issue (Nuttall et al., 1991). On the basis of the available evidence to date, it is suggested that the OHC tuning curves closely reflect isodisplacement tuning curves of the basilar membrane and that IHC and neural tuning curves reflect the net radial shear dis- placement between the basilar membrane and tectorial membrane. It should be pointed out that differences exist between laboratories and species in the measurement of basilar membrane mechanics, which have been discussed elsewhere (Robles et al., 1986; Ruggero et al., 1986; Ruggero and Rich, 1991b). For example, there is good agreement between isodisplacement basilar membrane tuning curves and neural tuning curves in the $7-10 \mathrm{kHz}$ region of the chinchilla cochlea (Robles et al., 1986). Small secondary peaks are found on the $\mathrm{HF}$ slopes of $\mathrm{OHC}$ tuning curves (Fig. 9), but not on the HF slopes of IHC tuning curves (see Fig. 9). Similar HF peaks and associated phase jumps have been described for basilar membrane isoresponse tuning curves (Rhode, 1971; Wilson and Johnstone, 1975; Wilson and Evans, 1983; Robles et al., 1986; Ruggero et al., 1991). HF shoulders and plateaus have been observed in basilar membrane isoresponse curves but only at levels that cause irreversible damage to the tuning curve (see Gummer and Johnstone, 1984). HF shoulder and phase plateaus have been inferred by Greenwood (1977; D. D. Greenwood, unpublished observations) from cochlear microphonic (CM) data obtained in the guinea pig by Dallos and Cheatham (1971) and in the gerbil by Schmeidt and Zwislocki (1977) and from neural recordings by Pfeiffer and Kim (1975), Kim et al. (1980), and Gummer and Johnstone (1984). Although there is some controversy over the demonstration of HF phase plateaus and tips on the basis of CM data (see Dallos and Cheatham, 1971), their presence in the mechanical tuning properties of the basilar membrane and in frequency tuning curves of auditory nerve fibers and $\mathrm{OHCs}$ is clear evidence that they are normal rather than pathological phenomena. In fact, their existence is predicted by models in which the phase and magnitude of the mechanical feedback from the OHCs are determined not only by the passive mechanics of the basilar membrane but by additional resonances provided by the mechanical properties of the tectorial membrane and the way it is coupled to the OHCs (Zwislocki, 1986; Allen, 1988).

\section{$I H C$ and $O H C$ transfer functions}

The findings reported here that OHCs in the basal turn of the guinea pig cochlea do not generate appreciable DC receptor potentials in response to $\mathrm{HF}$ tones until the $\mathrm{AC}$ level function saturates confirm earlier reports (Russell et al., 1986a; Cody and Russell, 1987) and lead to the suggestion that there are two electromechanical processes at work (Russell and Kössl, 1991). One of these processes is the potentially very rapid feedback of mechanical energy, which is an essential element in the frequency-selective process and is concerned with overcoming viscous forces at the CF (e.g., see Davis, 1983; Mountain et al., 1983; Neely and Kim, 1983). The other is a more vulnerable mechanism associated with minimizing the DC response of the $\mathrm{OHC}$ receptor potential and with optimizing the rapid feedback of mechanical activity to the cochlear partition. This latter component may correspond to the mechanical DC component that has been measured in isolated $\mathrm{OHCs}$ in response to transcellular current fields (Evans et al., 1988, 1991). According to current hypotheses (e.g., Patuzzi et al., 1989), the rapid (AC) feedback of mechanical energy from the OHCs is proportional to the magnitude of the $\mathrm{OHC}$ receptor potential and is very sensitive to the gain of the transduction process (which is directly related to the slope of the transducer function). For IHCs and OHCs in culture, the maximum gain does not occur at the zero operating point but on the depolarizing slope of the transducer function (Russell et al., 1986a,b). In OHCs in the intact organ 
of Corti, the transducer conductance is biased so that the transfer functions are more symmetrical and a large proportion of the transducer conductance will be open at rest. Therefore, the operating point is now shifted toward the region of maximum slope of the transfer function and the gain of transduction, and hence the feedback is maximized. It seems that the different locations of the operating points of the transfer functions of IHCs and OHCs reflect their different tasks. For maximum DC response and hence maximum transmitter release in response to HF tones, the IHC operating point is set to the point of maximum inflection on the transfer function, which corresponds to a resting transducer conductance of about $10 \%$ of the total (Russell and Kössl, 1991). For maximum transducer gain and feedback at low stimulus levels, the operating point is set at the point of maximum gain on the $\mathrm{OHC}$ transducer function, corresponding to a resting transducer conductance of about $50 \%$ of the total.

\section{References}

Allen JB (1988) Cochlear signal processing. In: Physiology of the ear (Jahn AF, Santos-Sacchi J, eds), pp 243-270. New York: Raven.

Anderson DJ, Rose JE, Hind JE, Brugge JF (1971) Temporal position of discharges in single auditory nerve fibres within the cycle of a sinewave stimulus: frequency and intensity effects. J Acoust Soc Am 49: 1131-1139.

Baden-Kristensen K, Weiss TF (1983) Receptor potentials of lizard hair cells with free standing stereocilia: responses to clicks. J Physiol (Lond) 335:699-722.

Brown AM, McDowell B, Forge A (1989) Acoustic distortion products can be used to monitor the effects of chronic gentamicin treatment. Hear Res 42:143-156.

Brown MC, Nuttall AL, Master RI (1983) Intracellular recordings from cochlear hair cells: effects of stimulation of the crossed olivocochlear efferents. Science 222:69-72.

Brownell WE, Bader CR, Bertrand D, de Ribaupierre Y (1985) Evoked mechanical responses of isolated cochlear outer hair cells. Science 227:194-196.

Cody AR, Mountain DC (1989) Low-frequency responses of inner hair cells: evidence for a mechanical origin of peak splitting. Hear Res 41:89-100.

Cody AR, Russell IJ (1987) The responses of hair cells in the basal turn of the guinea-pig cochlea to tones. I Physiol (Lond) 383:551569.

Dallos P (1986) Neurobiology of cochlear inner and outer hair cells: intracellular recordings. Hear Res 22:185-198.

Dallos P (1988) Cochlear neurobiology: some key experiments and concepts of the past two decades. In: Auditory function: neurobiological basis of hearing (Edelman GM, Gall WE, Cowan WM, eds), pp 153-188. New York: Wiley.

Dallos P, Cheatham MA (1971) Travel time in the cochlea and its determination from cochlea microphonic data. J Acoust Soc Am 49: 1140-1143.

Dallos P, Cheatham MA (1989) Nonlinearities in cochlear receptor potentials and their origins. J Acoust Soc Am 86:1790-1796.

Dallos P, Cheatham MA (1991) Effects of electrical polarization on inner hair cell receptor potentials. J Acoust Soc Am 87:1636-1647.

Davis H (1965) A model for transducer action in the cochlea. Cold Spring Harbor Symp Quant Biol 30:181-189.

Davis H (1983) An active process in cochlear mechanics. Hear Res 9:79-90.

Evans BN, Hallworth R, Dallos P (1988) Asymmetries in motile responses of outer hair cells in simulated in vivo conditions. In: Cochleax mechanisms: structure function and models (Wilson JP, Kemp DT, eds), pp 205-206. London: Plenum.

Evans BN, Hallworth R, Dallos P (1991) Outer hair cell electromotility: the sensitivity and vulnerability of the DC component. Hear Res 52:288-304.

Evans EF (1979) Neuroleptanaesthesia for the guinea-pig: an ideal anaesthetic procedure for long term physiological studies of the $\mathrm{co}$ chlea. Arch Otolaryngol 105:185-186.

Geisler CD, Rhode WS (1982) The phase of basilar membrane vibrations. J Acoust Soc Am 71:1201-1203.
Greenwood DD (1977) Empirical travel time functions on the basilar membrane. In: Ysychophysics and physiology of hearing (Evans EF, Wilson JP, eds), pp 43-53. London: Academic.

Gummer AW, Johnstone BM (1984) Group delay measurement from spiral ganglion cells in the basal turn of the guinea pig cochlea. J Acoust Soc Am 76:1388-1400.

Hudspeth AJ, Corey DP (1977) Sensitivity, polarity and conductance change in the response of vertebrate hair cells to controlled mechanical stimuli. Proc Natl Acad Sci USA 74:2407-2441.

Kemp DT (1978) Stimulated acoustic emissions from within the human auditory system. J Acoust Soc Am 64:1386-1391.

Kiang NY-S, Watanabe T, Thomas EC, Clarke LF (1965) MIT Research Monograph 35, Discharge patterns of single auditory fibres in the cat's auditory nerve. Cambridge, MA: MIT.

Kim DO, Molnar CE, Mathews JW (1980) Cochlear mechanics: nonlinear behaviour in two-tone responses and in ear-canal sound pressure. J Acoust Soc Am 67:1704-1721.

Kössl M, Russell IJ (1990) Modulation of voltage responses to 100 $\mathrm{Hz}$ tones by high frequency tones in cochlear hair cells. In: Mechanics and biophysics of hearing (Dallos P, Geisler CD, Mathews JW, Ruggero M, Steele CR, eds), pp 42-50. New York: Springer.

Liberman MC, Dodds LW (1984) Single-neuron labeling and chronic cochlear pathology. III. Stereocilia damage and alterations of threshold tuning curves. Hear Res 16:55-74.

Mountain DC, Cody AR (1989) Mechanical coupling between inner and outer hair cells in the mammalian cochlea. In: Cochlear mechanisms: structure function and models (Wilson JP, Kemp DT, eds), pp 153-160. London: Plenum.

Mountain DC, Hubbard AE, McMullen TA (1983) Electromechanical processes in the cochlea. In: Mechanics of hearing (de Boer E, Viergever MA, eds), pp 119-126. Delft, The Netherlands: Delft UP.

Neely ST, Kim DO (1983) An active cochlear model showing sharp tuning and high sensitivity. Hear Res 9:123-130.

Nuttall AL, Dolan DF, Avinash G (1991) Laser Doppler velocimetry of the basilar membrane. Hear Res 51:203-214

Patuzzi R, Johnstone BM, Sellick PM (1984) The alteration of the vibration of the basilar membrane produced by loud sound. Hear Res 13:99-100.

Patuzzi R, Yates GK, Johnstone BM (1989) Outer hair cell receptor currents and sensorineural hearing loss. Hear Res 42:47-72.

Pfeiffer RR, Kim DO (1975) Cochlear nerve fibre responses: distribution along the cochlear partition. J Acoust Soc Am 58:867-869.

Rhode WS (1971) Observations on the vibration of the basilar membrane in squirrel monkeys using the Mössbauer technique. J Acoust Soc Am 49:1218-1231.

Rhode WS, Robles L (1974) Evidence from Mössbauer experiments for nonlinear vibration in the cochlea. J Acoust Soc Am 55:588-596.

Robles L, Ruggero MA, Rich NC (1986) Basilar membrane mechanics at the base of the chinchilla cochlea. I. Input-output functions, tuning curves, and response phases. J Acoust Soc Am 80:1364-1374.

Ruggero MA, Rich NC (1991a) Furosemide alters organ of Corti mechanics: cvidence for feedback from outer hair cells upon the basilar membrane. J Neurosci 11:1057-1067.

Ruggero MA, Rich NC (1991b) Application of a commercially-manufactured Doppler-shift laser velocimeter to the measurement of basilar membrane vibration. Hear Res 51:215-230.

Ruggero MA, Robles L, Rich NC (1986) Basilar membrane mechanics at the base of the chinchilla cochlea. II. Responses to low-frequency tones and the relationship to microphonics and spike initiation in the VIII nerve. J Acoust Soc Am 80:1375-1383.

Ruggero MA, Rich NC, Recio A (1992) Basilar membrane responses to clicks. In: Auditory physiology and perception (Cazals Y, Demany L, Horner K, eds), in press, New York: Pergamon.

Russell IJ, Kössl M (1991) The voltage responses of hair cells in the basal turn of the guinea-pig cochlea. J Physiol (Lond) 435:493-511.

Russell IJ, Scllick PM (1978) Intracellular studies of hair cells in the mammalian cochlea. J Physiol (Lond) 284:261-290.

Russell IJ, Sellick PM (1983) Low-frequency characteristics of intracellularly recorded receptor potentials in guinea-pig cochlear hair cells. J Physiol (Lond) 338:179-206.

Russell IJ, Cody AR, Richardson GP (1986a) The responses of inner and outer hair cells in the basal turn of the guinea-pig cochlea and in the mouse cochlea grown in vitro. Hear Res 22:199-216.

Russell IJ, Richardson GP, Cody AR (1986b) Mechanosensitivity of mammalian auditory hair cells in vitro. Nature 321:517-519.

Saunders JC, Flock A (1986) Recovery of threshold shift in hair-cell 
stereocilia following exposure to intense stimulation. Hear Res 23: 233-244.

Schmeidt RA, Zwislocki JJ (1977) Comparison of sound transmission and cochlear microphonic characteristics in Mongolian gerbil and guinea-pig. J Acoust Soc Am 61:133-149.

Sellick PM, Patuzzi R, Johnstone BM (1982) Measurement of basilar membrane motion in the guinea pig using the Mössbauer technique. J Acoust Soc Am 61:133-149.

Sellick PM, Patuzzi R, Johnstone BM (1983) Comparison between the tuning properties of inner hair cells and basilar membrane motion. Hear Res 10:93-100.

Weiss TF (1982) Bidirectional transduction in vertebrate hair cells: a mcchanism for coupling mechanical and clectrical processes. Hear Res 7:353-360.

Wilson JP, Evans EF (1983) Some observations on the "passive" mechanics of the cat basilar membrane. In: Mechanisms of hearing (Webster WR, Aitkin LM, eds), pp 418-430. Clayton, Victoria, Australia: Monash UP.

Wilson JP, Johnstone JR (1975) Basilar membrane and middle ear vibration in guinea pig measured by capacitive probe. $J$ Acoust Soc Am 57:705-723.

Zwislocki JJ (1986) Analysis of cochlear mechanics. Hear Res 22:155169.

Zwislocki JJ (1988) Phase reversal of OHC response at high sound intensities. In: Cochlear mechanisms: structure function and models (Wilson JP, Kemp DT, eds), pp 163-168. London: Plenum.

Zwislocki JJ (1990) Active cochlear feedback: required structure and response phase. In: Mechanics and biophysics of hearing (Dallos P, Geisler CD, Mathews JW, Ruggero M, Steele CR, eds), pp 114-120. New York: Springer. 